\title{
Shop till you drop
}

\section{Baris · E. J. van den Bos}

Published online: 31 July 2020

(c) The Author(s) 2020

A 32-year-old male presented to the emergency department after an episode of vasovagal syncope during a shopping trip with his mother. He had a history of mild aortic regurgitation, but was otherwise healthy. Physical and laboratory examinations did not reveal any abnormalities. The electrocardiogram at presentation is shown in Fig. 1, the electrocardiogram five minutes after presentation is shown in Fig. 2.

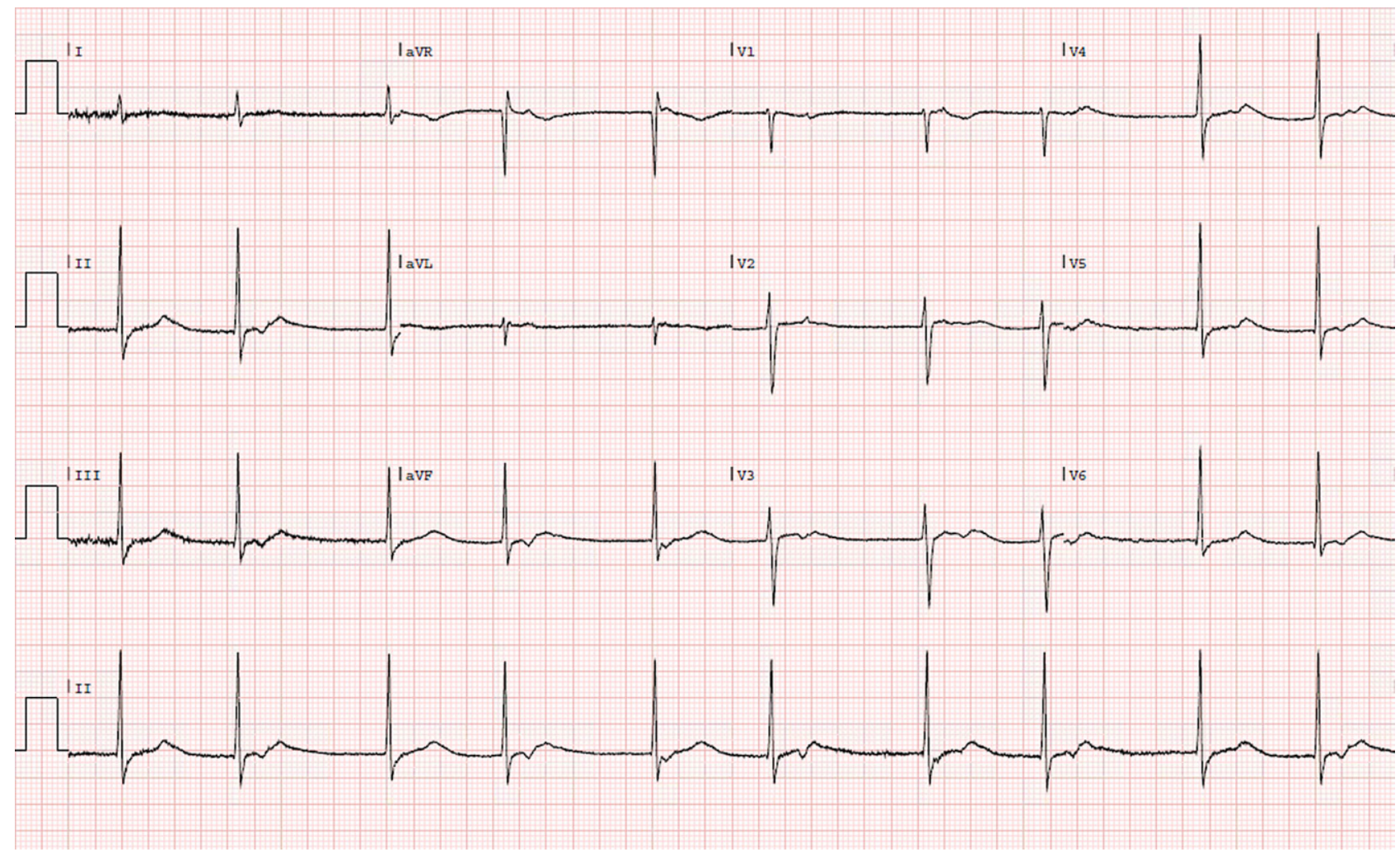

Fig. 1 Electrocardiogram at presentation

L. Baris · E. J. van den Bos $(\bowtie)$

Department of Cardiology, Albert Schweitzer Hospital,

Dordrecht, The Netherlands

e.j.vanden.bos@asz.nl 


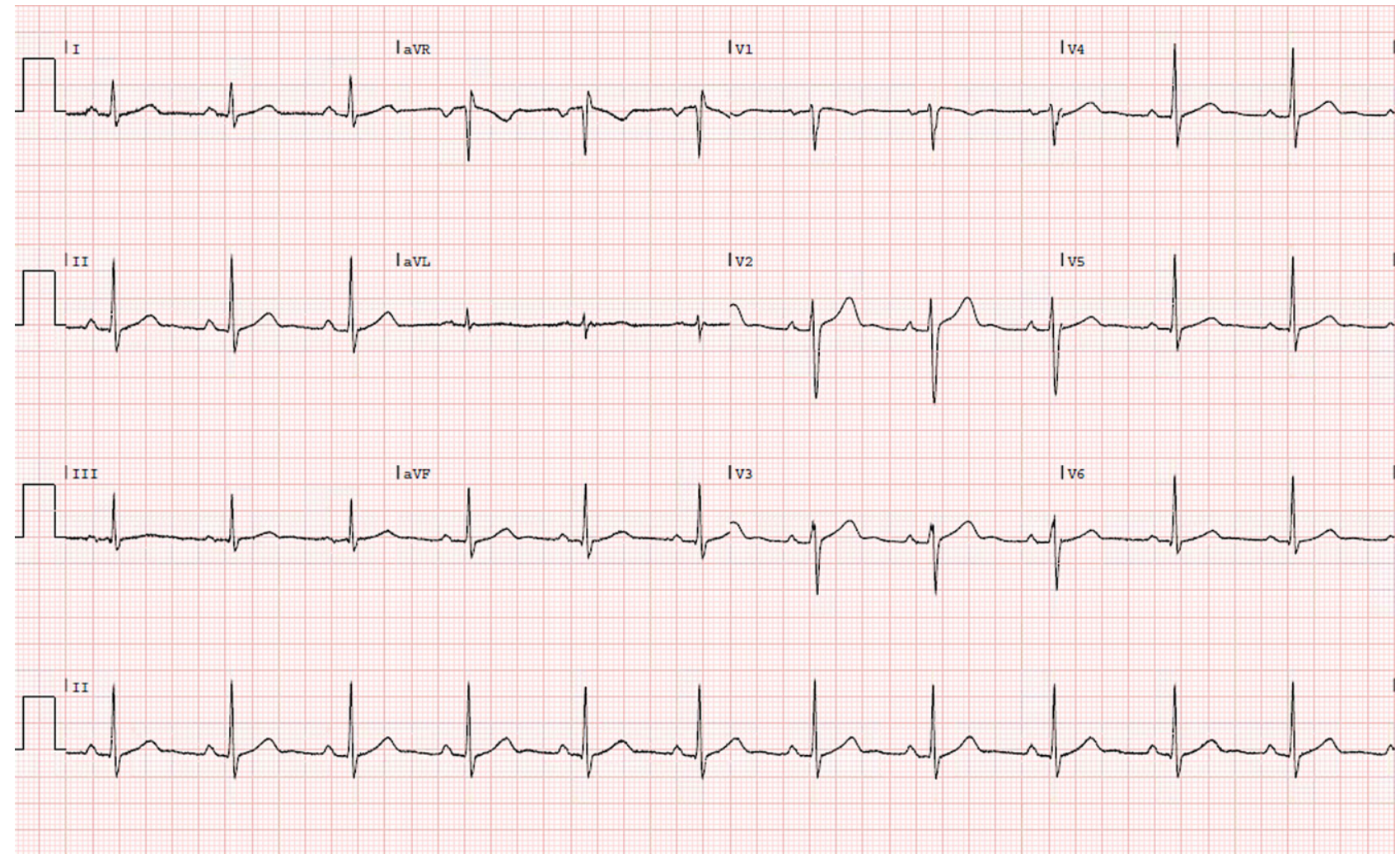

Fig. 2 Electrocardiogram $5 \mathrm{~min}$ after presentation

What is your diagnosis based on the electrocardiograms?

\section{Answer}

You will find the answer elsewhere in this issue.

Open Access This article is licensed under a Creative Commons Attribution 4.0 International License, which permits use, sharing, adaptation, distribution and reproduction in any medium or format, as long as you give appropriate credit to the original author(s) and the source, provide a link to the Creative Commons licence, and indicate if changes were made. The images or other third party material in this article are included in the article's Creative Commons licence, unless indicated otherwise in a credit line to the material. If material is not included in the article's Creative Commons licence and your intended use is not permitted by statutory regulation or exceeds the permitted use, you will need to obtain permission directly from the copyright holder. To view a copy of this licence, visit http://creativecommons.org/licenses/by/4.0/. 